\title{
Influence of the Net Promoter Score of Retailers on the Willingness of Consumers to Install Their Mobile App
}

\author{
https://doi.org/10.3991/ijim.v14i19.17027 \\ Atilla Wohllebe ${ }^{(凶)}$, Florian Ross \\ Szent István University, Kaposvár, Hungary \\ atilla.wohllebe@gmail.com \\ Szilárd Podruzsik \\ Corvinus University of Budapest, Budapest, Hungary
}

\begin{abstract}
Mobile apps have become increasingly important in the retail sector in recent years. A central challenge for retailers is the acquisition of new users for their mobile apps. A potentially interesting target group for this can be a company's existing, satisfied customer base, whereby customer satisfaction is often measured by the willingness to recommend the app or the Net Promoter Score. This paper investigates the influence of the willingness to recommend a retailer by consumers on their willingness to install a mobile app from this retailer. The influence of usage habits is also examined. The analysis of a survey of 105 consumers on a total of five retailers can confirm the hypotheses regarding the willingness to recommend a retailer and the Net Promoter Score (NPS) in particular: With the willingness to recommend, the willingness to install a retailer's app also increases.
\end{abstract}

Keywords-Mobile App, Net Promoter Score, Smartphone App, Likelihood to Recommend

\section{Introduction}

In recent years, the worldwide distribution of smartphones and consequently the distribution of mobile apps has increased significantly [1]. Apart from access to the Internet, apps are among the most frequently used and most important functionalities of smartphones [2]. Meanwhile they are used in many areas of life, some health, vacation, education or retail [3]-[5]. Accordingly, many companies have high expectations of increasing customer loyalty through their own mobile apps, so more and more companies are publishing their own mobile apps [6]. In 2019, the number of mobile apps available in the Google Play Store for the Android operating system was around 2.46 million [7].

This wide range of mobile apps means correspondingly high competitive pressure, which makes it increasingly difficult to acquire new app users via the usual stores of the operating system providers, while companies' expectations of the release of a mobile app continue to rise [8]. In the retail sector in particular, mobile apps offer 
numerous opportunities for sales activities due to their ability to address customers location-based [9], [10]. Active application users are also expected to generate higher sales in stationary retail [11], which makes an app an interesting additional offer for stationary retailers to their customers.

Especially for companies that offer a mobile app for smartphones as a supplement to other access and distribution channels, it may therefore make sense to consider ways of generating users that go beyond presenting the app in an app marketplace. It would be conceivable here, for example, to distribute paid advertising via channels such as display advertising or to address the company's own existing customer or user base via other channels. For retailers with an associated distance selling business, the catalogue or, in e-commerce, especially the web shop would be conceivable as a channel. The selection of the right target group is one of the challenges. Existing research suggests that users are more willing to adopt an app if they have a strong relationship with the brand behind the mobile app [12]. Because mobile apps are used by a wide variety of people, it is difficult to generalize about the factors that contribute to the adoption of companies and services [13]. In addition, in the area of education, for example, the acceptance of apps is also influenced by people's socioeconomic backgrounds [14].

Against this background, this paper examines in the specific context of retail how consumer satisfaction with a retailer affects the willingness to install a mobile app offered by the retailer. Customer satisfaction is measured with the Net Promoter Score (NPS), which is widely used in practice [15], [16]. On the basis of the existing literature, hypotheses are formulated, especially after critical evaluation of the NPS, and checked by means of several regression analyses. The usage habits of smartphone users in general and in the specific context of retail are also taken into account.

\section{$2 \quad$ Literature Review}

The literature review first considers existing findings on the consumer adoption and usage of mobile apps. This is followed by a review of the literature on the Net Promoter Score, which is also critically evaluated here. Finally, hypotheses for the later investigation are formed.

\subsection{Consumer adoption and usage of mobile apps}

The adoption of a mobile app by consumers and its active use is mainly highlighted in the literature as a trade-off between effort and benefit or expected added value. Potential app users weigh up the costs and benefits against each other to determine whether they want to use an app continuously [17]. The benefits of an app can lie, for example, in time convenience and interactivity, which both have a positive influence on consumer engagement with the application [18]. The attitude of consumers towards a particular app has a direct effect on their intention to actually use it. In contrast to this are negative emotions related to an app, which have a correspondingly negative effect on their intention to use it on a long-term basis [19]. In return, the 
benefits that a branded app offers pay off positively on the willingness of app users to recommend the app to others [20].

Overall, the brand of a company with all its facets, such as the brand attachment and the consumer's brand identification, is of great importance in connection with consumer adoption and the use of mobile apps. The use of a mobile app pays off positively on the brand attitude and product category involvement of app users [21]. A study on the impact of brand attachment and brand identification in the financial sector in Taiwan also shows, that they have a positive effect on mobile app adoption [12]. Ref. [22] also emphasizes that in addition to effort and performance expectancy, brand identification also has an effect on the active use of mobile apps.

Particularly noteworthy is the work of Ref. [23] regarding to the question of the overall effect of satisfaction with a company on the willingness to install its app. The authors find that the trust, users generally place in a company helps to create trust for the mobile app published by the company [23]. In addition to this, it can be noted that respect for the privacy of app users, for example, can be seen as a confidence-building factor that is conducive to adoption [24], [25].

\subsection{Measuring customer satisfaction using the net promoter score}

Although many factors related to user satisfaction with mobile apps are known, it is not possible to generalize across different industries or countries without restriction. The reason therefore is, that mobile apps are now published practically worldwide and for a wide variety of purposes [13]. In this respect, app development adapted to the customers of the respective company that wants to publish an app is an important component to increase the satisfaction of existing users [26]. However, it is unclear how customer satisfaction with the company can affect the acquisition of new app users when acquiring them from the existing customer base of a company. This requires a simple method for measuring customer satisfaction.

The Net Promoter Score (NPS) was introduced in 2003 as "The One Number You Need to Grow" for measuring customer satisfaction. At its core is the question to customers, how probability they would recommend a company, a brand or a service to a friend or colleague. The respondents give their answer on a scale of 0 (unlikely) to 10 (very likely), where those who answer with 9 or 10 are called promoters. Those who answer with 0 to 6 are called detractors, and those who answer with 7 or 8 are called indifferent. Finally, the NPS is calculated as the difference between the proportion of promoters and detractors and can thus lie between +100 (promoters only) and -100 (detractors only) percent [15].

The basically simple method of the NPS (cf. Ref. [27]) is also critically discussed in science - especially against the background of its application for measuring customer satisfaction. The NPS, for example, does not live up to its claim as the only necessary metric for measuring customer satisfaction [16] and is also not suitable as a method for measuring customer loyalty [28]. In particular, the NPS can only be one of several methods for measuring customer satisfaction [27], [29]-[31], especially since the NPS alone does not provide any insights into concrete improvement potentials [29]. It is also noteworthy that, for example, the survey method, i.e. the channel on 
which customers are asked to rate seems to have an influence on the NPS [32]. Similar observations were also made for gender [33].

Despite all the criticisms, NPS has been used several times from the beginning, not only in practice but also in research [27]-[31], [34], [35]. Originally developed by Ref. [15] as a measure correlating with company growth, satisfaction the NPS is repeatedly used as a method for measuring customer, here expressed by the intention to recommend it as the highest form of customer satisfaction [28], [35], [36]. In this respect, the NPS may be regarded as one of the most popular methods in business practice for measuring customer satisfaction.

\subsection{Hypothesis}

Based on existing findings on the adoption and use of mobile applications, a number of hypotheses are derived below. The formulated hypotheses are tested empirically in our research.

The basis are the research results, which emphasize the importance of the brand and consumers' attachment to the brand and the trust of consumers in a company for mobile app adoption. Accordingly, the hypothesis is derived that the willingness to recommend a company increases the willingness to install an app of this company [12], [21]-[23]:

H1: The willingness of consumers to recommend a company increases the willingness of consumers to install an app from that company.

Similarly, it is assumed that the NPS calculated by Ref. [15] from the willingness to recommend a company, increases the willingness to install its app, since a high NPS can be considered as an indication of highly satisfied customers [15], [36]:

H2: With the NPS related to a company, the willingness to install an app of this company increases.

The activity of app users also increases the turnover generated in online and stationary retail trade [11] and those users who have a particular affinity for the internet and shopping are likely to benefit from installing a mobile app for this purpose [17]. Regarding to that, the following hypotheses are also put forward on how people's internet usage and online shopping habits affect their willingness to install a mobile app from a stationary retailer [11]:

H3a: The willingness to install an app from a retailer increases with the frequency of Internet use.

$H 3 b$ : The willingness to install an app from a retailer increases with the frequency of smartphone use.

H3c: The willingness to install an app from a retailer increases with frequency of mobile internet use.

$H 3 d$ : The willingness to install an app from a retailer increases with online shopping frequency.

H3e: The willingness to install an app from a retailer increases with mobile online shopping frequency. 
In addition, the phenomenon found by Ref. [33] that the NPS differs according to gender will be examined. Accordingly, a gender-specific hypothesis will be formulated:

H4: There is a significant difference in the willingness to recommend the NPS depending on the gender of the respondents.

\section{Empirical Research}

In the following, first the study design and data collection are described, followed by a description of the statistical methods used to analyse the data.

\subsection{Survey design and data collection}

Using an online questionnaire conducted between January and May 2020 in Germany, we examined the formulated hypotheses.

For this purpose, consumers in Germany were first identified by gender and age.

Subsequently, they will be asked about the frequency of use of:

a) The internet

b) The smartphone

c) The internet on the smartphone

d) Online shopping

e) Mobile online shopping

The respondents are asked to rate the frequency of use on a scale of 1 (very rarely) to 6 (very often).

In the next step, respondents are asked to indicate, for a total of five retailers in Germany, the extent to which they are willing to recommend them to friends or colleagues. In the style of the NPS, the information is given on a scale of 1 (very unlikely) to 10 (very likely).

For the same five retailers, the final step is to ask to what extent respondents are willing to install an application from these retailers. This question is asked for each retailer, with the answers being given on a scale of 1 (very unlikely) to 6 (very likely). In addition, the respondent may indicate that the application has already been installed (which is rated 7 in the later statistical evaluation and analysis).

The questionnaire was answered a total of 113 times, leaving 105 valid responses with incomplete questionnaires. Figure 1 shows the distribution of answers by gender and age group. It should be noted that the group of 20 to 29 -year olds is particularly strongly represented. In contrast, the age groups over 40 years of age are hardly represented. 


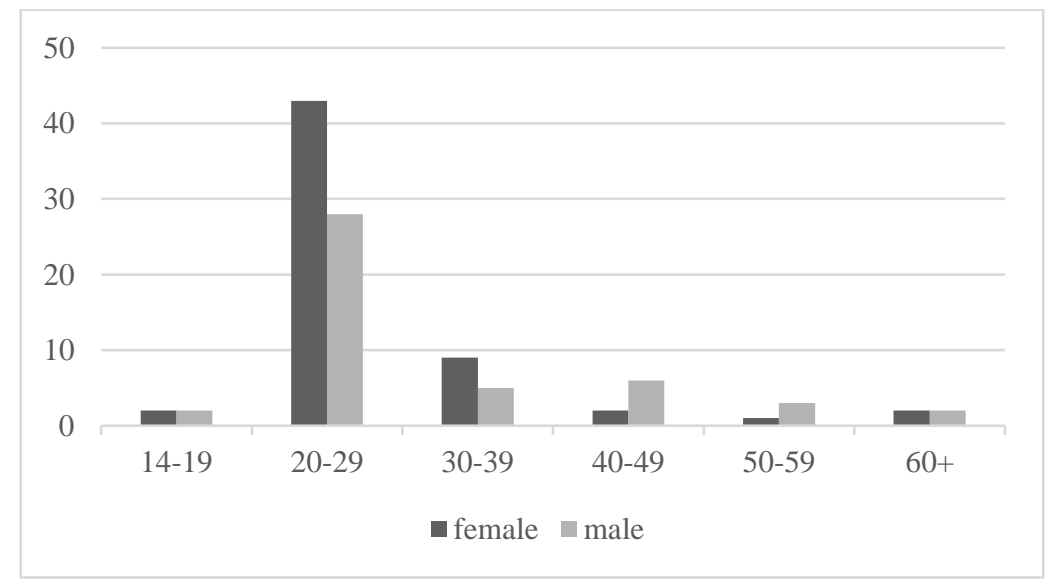

Fig. 1. Number of Replies by Age Group and Gender

In addition, figure 2 shows the average recommendation probability or the average installation probability of an app by retailers. Here it is particularly noteworthy that for all retailers on average the willingness to recommend is higher than the willingness to install an app from the particular retailer.

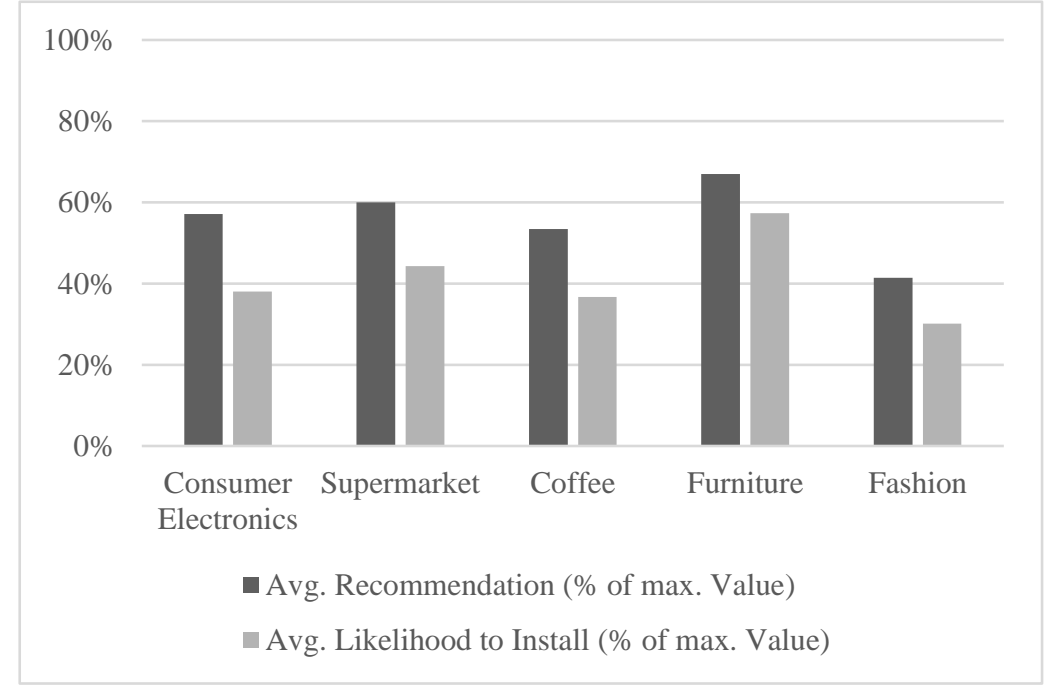

Fig. 2. Recommendation and Installation - Average Values per Retailer

For better comparability, the values in figure 2 are given as a percentage of the maximum achievable value (recommendation: 10; app installation: 6). 


\subsection{Methodology}

In order to test the hypotheses $\mathrm{H} 1, \mathrm{H} 2$ and $\mathrm{H} 3 \mathrm{a}-\mathrm{H} 3 \mathrm{e}$, regression analyses are carried out, whereby a linear relationship is assumed between the willingness to recommend or the NPS or the variables on usage habits and the willingness to install an app. The latter represents the respective dependent variable.

Using simple linear regression analysis, we investigate how the independent variable (i.e. the willingness to recommend or variables on usage habits) affects the dependent variable of the willingness to install an app [37]. Using the ordinary least squares method (OLS), an attempt is made to show the relationship between the two variables under investigation in a linear relationship. The deviations of the calculated regression line from the values actually observed should be as small as possible.

The results of each regression analysis are evaluated and interpreted in several steps: An F-test is used to check the overall quality of the model (null hypothesis: all coefficients are equal to 0 ). The empirical coefficient of determination $\mathrm{R}^{2}$ checks the extent to which the model with its independent variables explains the variance of the dependent variable. The individual regression coefficients give magnitude over the strength of the relationship, with the p-value of the t-statistic of the regression coefficient indicating whether the individual regression coefficient has a significant influence on the dependent variable [38].

In order to test hypothesis $\mathrm{H} 4$, we will first examine the extent to which both groups (male, female) show equal variances. To test the equality of the variances, a Levene test for homoscedasticity is performed (null hypothesis: the variances of the samples are equal) [39]. Then, if the variance in the populations is equal, a twosample t-test is performed, or if the variance is unequal, a Welch test is performed (null hypothesis in each case: the mean values of the populations are equal [40], [41]. As a result, a statement can be made as to the extent to which H4 that the NPS differs depending on gender, is to be accepted or rejected.

\section{$4 \quad$ Results}

The results of the statistical evaluation for the individual hypotheses are presented below:

\subsection{Willingness to recommend and to install}

First of all, it is checked to what extent the willingness to recommend has an effect on the willingness to install an app.

H1: The willingness of consumers to recommend a company increases the will-

ingness of consumers to install an app from that company.

Figure 3 shows the results of the linear, simple regression analysis. The model explains the influence of the willingness to recommend an app installation significantly $(\mathrm{F}=258.26, \mathrm{p}=.0000)$. The model explains one third of the variance of the dependent variable $\left(\mathrm{R}^{2}=.3306\right)$. 
Paper-Influence of the Net Promoter Score of Retailers on the Willingness of Consumers to Install...

\begin{tabular}{|c|c|c|c|c|c|c|}
\hline Source & SS & $d f$ & MS & Number of obs & $=$ & 525 \\
\hline Model & 535.850016 & 1 & 535.850016 & Prob > F & $=$ & 0.0000 \\
\hline Residual & 1085.14808 & 523 & 2.07485292 & R-squared & $=$ & 0.3306 \\
\hline Total & 1620.9981 & 524 & 3.09350782 & Root MSE & $=$ & 1.446 \\
\hline
\end{tabular}

\begin{tabular}{r|rrrrrr}
\hline Like_AppInst & Coef. & Std. Err. & $t$ & $\mathrm{P}\rangle|\mathrm{t}|$ & [95\% Conf. Interval] \\
\hline Like_Recomm & .374935 & .0233307 & 16.07 & 0.000 & .3291016 & .4207685 \\
_cons & .3856006 & .1445895 & 2.67 & 0.008 & .1015531 & .6696482 \\
\hline
\end{tabular}

Fig. 3. Regression Results for $H 1$, based on collected survey data

The result shows that with the readiness of a recommendation the readiness of an app installation increases significantly $(\beta=.3749, \mathrm{t}=16.07, \mathrm{p}=.000)$. When interpreting these results, it is important to note that the willingness to install an app was measured on a scale of 1 to 6 .

\subsection{NPS and willingness to install}

To test the second hypothesis, which examines the connection between (companyrelated) NPS and the willingness to install apps, the NPS is calculated for each company.

H2: With the NPS related to a company, the willingness to install an app of this company increases.

For the purpose to test the connection between NPS and willingness to install apps, the share of detractors is deducted from the share of promoters. At the same time the average willingness to install an app is calculated for each company. Then a simple regression analysis is calculated.

Table 1 shows the number of detractors, indifferents and promoters as well as the NPS and the average likelihood to install an app from that company.

Table 1. NPS and Likelihood to Install App per Merchant, based on collected survey data

\begin{tabular}{|l|c|c|c|c|c|}
\hline & M1 & M2 & M3 & M4 & M5 \\
\hline Detractors & 61 & 47 & 64 & 44 & 82 \\
\hline Indifferent & 35 & 48 & 25 & 28 & 17 \\
\hline Promoter & 9 & 10 & 16 & 33 & 6 \\
\hline NPS & -49.5238 & -35.2381 & -45.7143 & -10.4762 & -72.3810 \\
\hline Avg. Likelihood to install & 2.2762 & 2.6667 & 2.2000 & 3.4381 & 1.8095 \\
\hline
\end{tabular}

The subsequent regression examines the influence of the NPS on the average willingness to install an app of this merchant.

Although the number of cases is very low at 5 for a linear regression and well below the value of 20 recommended for a regression analysis with an independent variable, the results can be interpreted due to the good F-test $(F=67.46, p=.0038)$, the 
high $\mathrm{R}^{2}\left(\mathrm{R}^{2}=.9574\right)$ and significant result of the checked variable $(\mathrm{t}=8.21, \mathrm{p}=.004)$ (cf. Ref. [38]).

\begin{tabular}{|c|c|c|c|c|c|c|c|}
\hline Source & SS & $d f$ & MS & \multirow{2}{*}{\multicolumn{2}{|c|}{$\begin{array}{l}\text { Number of obs } \\
F(1,3) \\
\text { Prob > F }\end{array}$}} & $=$ & \\
\hline Model & 1.45743791 & 1 & 1.45743791 & & & $=$ & 0.0038 \\
\hline Residual & .064811518 & 3 & .021603839 & \multicolumn{2}{|c|}{ R-squared } & & 0.9574 \\
\hline Total & 1.52224943 & 4 & .380562358 & \multicolumn{2}{|c|}{$\begin{array}{l}\text { Adj R-squared } \\
\text { Root MSE }\end{array}$} & $=$ & 14698 \\
\hline Like_AppInst & Coef. & Std. Err. & $\mathrm{t}$ & $P>|t|$ & {$[95 \% \mathrm{C}$} & 1. & Interval] \\
\hline NPS & .0267902 & .0032617 & 8.21 & 0.004 & .016 & & .0371705 \\
\hline _cons & 3.621146 & .1539097 & 23.53 & 0.000 & 3.1313 & & 4.110955 \\
\hline
\end{tabular}

Fig. 4. Regression Results for $H 2$, based on collected survey data

The results show a significantly positive influence of NPS on the willingness to install a retailer's app $(\beta=.0268, t=8.21, p=.004)$. It should be noted here that the NPS is measured on a scale of -100 to +100 , while the readiness to install the app is measured on a scale of 1 to 6 .

For example, if it were possible to convert 10 detractors to indifferent customers for M1, the NPS would increase from -49.5238 to -40.0014 . As a result, the willingness to install an app for this retailer would increase by about 0.2679 points - an increase of more than 10 percent measured by the respondents' current willingness to install the retailer's app (see table 1).

\subsection{Habits of use}

A multiple linear regression is used to investigate possible correlations between the respondents' usage habits and the willingness of the retailers mentioned to install the app. Figure 5 shows the results of this regression analysis.

The model can be regarded as significant overall $(\mathrm{F}=15.32, \mathrm{p}=.0000)$, but has a lower explanatory power compared to the willingness to recommend or NPS models $\left(\mathrm{R}^{2}=.1286\right)$. 


\begin{tabular}{|c|c|c|c|c|c|c|}
\hline Source & SS & $d f$ & MS & Number of obs & & 52 \\
\hline Model & 208.504455 & 5 & 41.7008911 & Prob $>\mathrm{F}$ & & 0.00 \\
\hline Residual & 1412.49364 & 519 & 2.72156771 & R-squared & & \\
\hline Total & 1620.9981 & 524 & 3.09350782 & Root MSE & & 1.64 \\
\hline
\end{tabular}

\begin{tabular}{r|rrrrrr}
\hline Like_AppInst & Coef. & Std. Err. & $t$ & $\mathrm{P}>|\mathrm{t}|$ & [95\% Conf. Interval] \\
\hline Freq_IntUse & -.3889712 & .0938636 & -4.14 & 0.000 & -.5733705 & -.204572 \\
Freq_PhoneUse & -.0577617 & .1150671 & -0.50 & 0.616 & -.2838164 & .1682929 \\
Freq_IntPhoneUse & .0728948 & .0892991 & 0.82 & 0.415 & -.1025373 & .2483269 \\
Freq_IntShop & -.1164371 & .0788327 & -1.48 & 0.140 & -.2713075 & .0384334 \\
Freq_PhoneShop & .4190884 & .0693726 & 6.04 & 0.000 & .2828029 & .555374 \\
_cons & 3.712577 & .4225676 & 8.79 & 0.000 & 2.882424 & 4.542731
\end{tabular}

Fig. 5. Regression Results for $H 3 a-H 3 e$, based on collected survey data

Only the frequency of shopping with the mobile phone explains the willingness to install an app significantly and in the sense of the hypotheses $(B=.4191, t=6.04, p=$ $.000)$.

The frequency of Internet use has a significant influence on the willingness to install an app, but contrary to the hypothesis $\mathrm{H} 3 \mathrm{a}$, this is even negative $(B=-.3890, \mathrm{t}=$ $4.14, \mathrm{p}=.000)$.

Table 2. Results of Analysis Regarding Usage Habits, based on collected survey data

\begin{tabular}{|l|l|}
\hline \multicolumn{1}{|c|}{ Hypothesis } & \multicolumn{1}{c|}{ Result } \\
\hline H3a: Internet usage & Rejected - Negative influence \\
\hline H3b: Smartphone usage & Rejected \\
\hline H3c: Mobile internet usage & Rejected \\
\hline H3d: Online shopping frequency & Rejected \\
\hline H3e: Mobile online shopping frequency & Accepted \\
\hline
\end{tabular}

\subsection{Gender-dependent differences}

The fourth hypothesis, derived from the work of Ref. [33], postulates differences in the willingness to recommend the study depending on the gender of the respondents:

H4: There is a significant difference in willingness to recommend depending on the gender of the respondents.

To test the hypothesis, a two-sample t-test is performed assuming equal variances. For this purpose, the mean values of the willingness to recommend the test depending on gender are formed and compared with each other.

Table 3 shows the number of observations, mean value of willingness to recommend and variance of the same for both groups. 
Table 3. Willingness to Recommend by Gender, based on collected survey data

\begin{tabular}{|l|c|c|}
\hline & Male & Female \\
\hline Number of observations & 230 & 295 \\
\hline Mean & 5.0043 & 6.0305 \\
\hline Variance & 7.2009 & 6.8936 \\
\hline
\end{tabular}

Using the Levene test, the condition of equal variances of the two groups, male and female, is first checked. The null hypothesis that the variances of the groups are equal is not rejected $(\mathrm{F}=.649, \mathrm{p}=.421)$.

In the subsequent t-test, the null hypothesis that the mean values of the two groups are equal is rejected $(\mathrm{t}=4,404, \mathrm{p}=.0000)$.

The hypothesis $\mathrm{H} 4$ that there is a significant difference in the willingness to recommend is considered confirmed.

\section{Summary}

Altogether, the study examined hypotheses from four areas on the influence on the willingness to install an app by a retailer.

In particular, the hypotheses at the core of this study, that the willingness to recommend (H1) and the NPS (H2) have a positive effect on the willingness to install an app, can be confirmed.

Also the result of the work of Ref. [33] that there are gender dependent differences in NPS (H4) could be confirmed.

Table 4. Summary of the results, based on statistical evaluation

\begin{tabular}{|l|l|}
\hline \multicolumn{1}{|c|}{ Hypothesis } & \multicolumn{1}{c|}{ Result } \\
\hline$H 1:$ Recommendation & Confirmed \\
\hline$H 2:$ NPS & Confirmed \\
\hline H3a: Internet usage & Rejected - Negative influence \\
\hline H3b: Smartphone usage & Rejected \\
\hline H3c: Mobile internet usage & Rejected \\
\hline H3d: Online shopping frequency & Rejected \\
\hline H3e: Mobile online shopping frequency & Confirmed \\
\hline H4: Gender-dependent differences & Confirmed \\
\hline
\end{tabular}

The results are less clear with regard to usage habits: Here, only the positive influence of the frequency of online shopping via mobile phone on the willingness to install the app could be confirmed (H3e). Smartphone usage frequency, mobile Internet usage frequency and online shopping frequency, on the other hand, have no significant influence $(\mathrm{H} 3 \mathrm{~b}-\mathrm{H} 3 \mathrm{~d})$. Internet usage frequency even has a negative effect on the willingness to install a retailer's mobile app (H3a). Table 4 summarizes the results of the analysis for all hypotheses.

With regard to the limitations of this elaboration, the thematic and geographical focus and the survey method are to be named in particular. Thus, the survey conducted 
here asks for the willingness to recommend or install an app by means of a questionnaire and asks the interviewees to give their own assessment when assessing their usage habits. As is usual with such surveys, however, the actual recommendation or installation or the actual usage habits observed in a quantifiable manner are not collected.

With regard to the thematic and geographical focus, it should be noted that the data collected was collected exclusively in Germany and exclusively for the retail trade. In this respect, the transferability of the results to other sectors or countries is not possible without further examination.

Methodologically, the hypothesis $\mathrm{H} 2$, which examines a correlation between NPS and app installation readiness at the retailer level, should be tested: Since the survey asked for the values of only five retailers, the corresponding regression analysis is carried out with a very small number of cases. Although the evaluations on the quality of the model are consistently positive, these results cannot be transferred without restrictions either.

\section{Conclusion}

The aim of the elaboration is to investigate the connection between the willingness to recommend a retailer and the willingness to install an app of this retailer.

After an introductory explanation of the relevance of mobile apps in the corporate context and in the retail sector in particular, a review of the existing literature shows that up to now, the willingness to recommend a company or to recommend an app as a target variable has been investigated. However, how the willingness to recommend a retailer affects the willingness of consumers has not been investigated so far. In particular the elaboration of Ref. [23] suggests, however, that - analogous to the trust that is transferred from companies to apps - the willingness to recommend or the NPS could have a positive effect here.

The data collected in the course of the study and evaluated by means of statistical methods can confirm this assumption and thus make a valuable contribution to the business practice of acquiring new App users: Especially the existing, satisfied customer base of a company is a promising target group if new App users are to be acquired with limited resources.

The investigation of the willingness to install apps in relation to usage habits shows in most cases that the hypotheses put forward have to be rejected. Only those customers of a company who have a particularly high affinity for shopping via the smartphone represent a potentially attractive target group for advertising campaigns for the marketing of a retailer's mobile app.

Three things can be regarded as interesting for further research projects: Firstly, the examination of the extent to which the results can be transferred to sectors other than retail or to countries other than Germany; secondly, with regard to the NPS per retailer, a renewed, more comprehensive investigation with more retail companies; thirdly, the validation of the results determined here in the context of a case study in applied business practice. 


\section{$7 \quad$ References}

[1] Eurostat, "Religious/spiritual commitments and psychiatric practice." 2016, [Online]. Available: https://ec.europa.eu/eurostat/documents/2995521/7771144/9-20122016-BP-DE. pdf/0aba7cec-63d5-411f-ad33-9dd91aa036e4.

[2] VuMA, "Beliebteste Anwendungen und Funktionen auf den persönlichen Handys/Smartphones der Apple-Kunden in Deutschland im Vergleich mit der Bevölkerung im Jahr 2017," Statista, 2017. https://de.statista.com/statistik/daten/studie/856 984/umfrage/umfrage-unter-apple-kunden-zu-den-beliebtesten-funktionen-auf-dem-smartp hone. https://doi.org/10.1007/978-3-322-85297-7_8

[3] M. Kalogiannakis and S. Papadakis, "Combining mobile technologies in environmental education: a Greek case study,” IJMLO, vol. 11, no. 2, p. 108, 2017, https://doi.org/10.150 4/ijmlo.2017.10005249

[4] BITKOM, "Mobile Apps - Nutzung auf Reisen in Deutschland 2020," Statista, 2020. https://de.statista.com/statistik/daten/studie/728171/umfrage/nutzung-von-apps-auf-reisenin-deutschland/ (accessed Aug. 26, 2020).

[5] gfs.bern, "Schweiz - Nutzung Apps Messung Blutdruck/-zucker 2020," Statista, 2020. https://de.statista.com/statistik/daten/studie/527323/umfrage/umfrage-in-der-schweiz-zurnutzung-von-apps-zur-messung-von-blutdruck-zucker/ (accessed Aug. 26, 2020). https:// doi.org/10.4414/saez.2005.11170

[6] BITKOM, "Aus Entwicklersicht: Was sind die vorrangigen Gründe für Ihr Unternehmen in die Entwicklung mobiler Anwendungen zu investieren?," Statista, 2011. https://de.statista.com/statistik/daten/studie/196892/umfrage/beweggruende-vonunternehmen-fuer-die-entwicklung-von-apps/ (accessed Oct. 19, 2019). https://doi.org/10. 1007/978-3-663-07976-7 2

[7] Appfigures, "Anzahl der verfügbaren Apps in den Top App-Stores im 2. Quartal 2019," Statista, 2019. https://de.statista.com/statistik/daten/studie/208599/umfrage/anzahl-der-app s-in-den-top-app-stores.

[8] BITKOM, "Umsatz mit mobilen Apps in Deutschland in den Jahren 2008 bis 2018 sowie eine Prognose für 2019 (in Millionen Euro)," Statista, 2019. https://de.statista.com/stati stik/daten/studie/173810/umfrage/umsatz-mit-mobilen-apps-in-deutschland-seit-2009 (accessed Oct. 19, 2019).

[9] D. S. Verma and D. Verma, "Managing Customer Relationships through Mobile CRM In Organized retail outlets," International Journal of Engineering Trends and Technology IJETT, vol. 4, no. 5, pp. 1697-1701, 2013, Accessed: Jul. 12, 2020. [Online]. Available: http://ijettjournal.org/archive/ijett-v4i5p76.

[10] N. Allurwar, B. Nawale, and S. Patel, "Beacon for Proximity Target Marketing," International Journal Of Engineering And Computer Science, vol. 5, no. 5, pp. 1635916364, 2016, [Online]. Available: https://www.ijecs.in/index.php/ijecs/article/download/ 1125/1023/. https://doi.org/10.18535/ijecs/v5i5.08

[11] I. M. Dinner, H. J. van Heerde, and S. Neslin, "Creating Customer Engagement Via Mobile Apps: How App Usage Drives Purchase Behavior," Social Science Research Network, Rochester, NY, SSRN Scholarly Paper ID 2669817, Oct. 2015. Accessed: Nov. 26, 2019. [Online]. Available: https://papers.ssrn.com/abstract=2669817. https://doi.org/ $10.2139 / \mathrm{ssrn} .2669817$

[12] K.-F. Peng, Y. Chen, and K.-W. Wen, "Brand relationship, consumption values and branded app adoption," Industrial Management \& Data Systems, vol. 114, no. 8, pp. 11311143, Jan. 2014, https://doi.org/10.1108/imds-05-2014-0132. 
[13] R. Ghnemat and E. Jaser, "Classification of Mobile Customers Behavior and Usage Patterns using Self-Organizing Neural Networks," International Journal of Interactive Mobile Technologies (iJIM), vol. 9, no. 4, Art. no. 4, Sep. 2015, Accessed: May 14, 2020. [Online]. Available: https://online-journals.org/index.php/i-jim/article/view/4392. https:// doi.org/10.3991/ijim.v9i4.4392

[14] S. Papadakis, N. Zaranis, and M. Kalogiannakis, "Parental involvement and attitudes towards young Greek children's mobile usage," International Journal of Child-Computer Interaction, vol. 22, p. 100144, Dec. 2019, https://doi.org/10.1016/j.ijcci.2019.100144.

[15] F. F. Reichheld, "The One Number You Need to Grow," Harvard Business Review, no. December 2003, Dec. 01, 2003.

[16] N. I. Fisher and R. E. Kordupleski, "Good and bad market research: A critical review of Net Promoter Score," Appl Stochastic Models Bus Ind, vol. 35, no. 1, pp. 138-151, Jan. 2019, https://doi.org/10.1002/asmb.2417.

[17] S. Kang, "Factors influencing intention of mobile application use," IJMC, vol. 12, no. 4, p. 360, 2014, https://doi.org/10.1504/ijmc.2014.063653.

[18] S. Kim and T. H. Baek, "Examining the antecedents and consequences of mobile app engagement," Telematics and Informatics, vol. 35, no. 1, pp. 148-158, Apr. 2018, https:// doi.org/10.1016/j.tele.2017.10.008

[19] Y. Ding and K. Chai, "Emotions and continued usage of mobile applications," Industrial Management \& Data Systems, vol. 115, no. 5, pp. 833-852, 2015. https://doi.org/10.1108/ imds-11-2014-0338

[20] L. Stocchi, N. Michaelidou, N. Pourazad, and M. Micevski, "The rules of engagement: how to motivate consumers to engage with branded mobile apps," Journal of Marketing Management, vol. 34, no. 13-14, pp. 1196-1226, Sep. 2018, https://doi.org/10.1080/02672 $\underline{57 x .2018 .1544167}$

[21] S. Bellman, S. Treleaven-Hassard, J. Robinson, D. Varan, and R. Potter, "Brand communication with branded smartphone apps: First insights on possibilities and limits," GfK Marketing Intelligence Review, vol. 5, no. 2, pp. 24-27, 2013. https://doi.org/10.247 $\underline{\text { 8/gfkmir-2014-0014 }}$

[22] L. Wu, "Factors of continually using branded mobile apps: the central role of app engagement," IJIMA, vol. 9, no. 4, p. 303, 2015, https://doi.org/10.1504/ijima.2015.07288 $\underline{4}$.

[23] V. Jham, "Adoption of mobile marketing through smart phones apps," Journal of Emerging Trends in Economics and Management Sciences, vol. 9, no. 2, pp. 52-64, 2018, https://www.researchgate.net/profile/Vimi_Jham/publication/336771217_Adoption_of_M obile Marketing Through Smart Phones Apps/links/5db178b492851c577eba78d7/Adop tion-of-Mobile-Marketing-Through-Smart-Phones-Apps.pdf. https://doi.org/10.21511/im. 16(3).2020.09

[24] Z. Belkhamza and M. A. F. Niasin, "The Effect of Privacy Concerns on Smartphone App Purchase in Malaysia: Extending the Theory of Planned Behavior," International Journal of Interactive Mobile Technologies (iJIM), vol. 11, no. 5, Art. no. 5, Jul. 2017, Accessed: May 14, 2020. [Online]. Available: https://online-journals.org/index.php/i-jim/article/view /6961. https://doi.org/10.3991/ijim.v11i5.6961

[25] X. Wang, Z. Hong, Y. C. Xu, C. Zhang, and H. Ling, "Relevance judgments of mobile commercial information: Relevance Judgment of Mobile Commercial Information," J Assn Inf Sci Tec, vol. 65, no. 7, pp. 1335-1348, Jul. 2014, https://doi.org/10.1002/asi.23060.

[26] A. Hussain, E. O. C. Mkpojiogu, N. Nabeel, and A. Alathwari, "Users Perception of the Mobile Usability of a Global Bicycle Sharing Platform," International Journal of Interactive Mobile Technologies (iJIM), vol. 13, no. 11, Art. no. 11, Nov. 2019, Accessed: 
May 14, 2020. [Online]. Available: https://online-journals.org/index.php/i-jim/article/ view/11298. https://doi.org/10.3991/ijim.v13i11.11298

[27] P. Korneta, "Net promoter score, growth, and profitability of transportation companies," International Journal of Management and Economics, vol. 54, no. 2, pp. 136-148, Jun. 2018, https://doi.org/10.2478/ijme-2018-0013.

[28] K. Kristensen and J. Eskildsen, "Is the NPS a trustworthy performance measure?," The TQM Journal, vol. 26, no. 2, pp. 202-214, Mar. 2014, https://doi.org/10.1108/tqm-032011-0021.

[29] M. A. Laitinen, "Net Promoter Score as Indicator of Library Customers' Perception," Journal of Library Administration, vol. 58, no. 4, pp. 394-406, May 2018, https://doi.org/ $\underline{10.1080 / 01930826.2018 .1448655}$

[30] B. Leisen Pollack and A. Alexandrov, "Nomological validity of the Net Promoter Index question," Journal of Services Marketing, vol. 27, no. 2, pp. 118-129, May 2013, https:// doi.org/10.1108/08876041311309243.

[31] P. C. Mandal, "Net promoter score: a conceptual analysis," IJMCP, vol. 8, no. 4, p. 209, 2014, https://doi.org/10.1504/ijmcp.2014.066899.

[32] J. G. Temple, B. J. Burkhart, and A. R. Tassone, "Does the Survey Method Affect the Net Promoter Score?," in Advances in Usability and User Experience, vol. 972, T. Ahram and C. Falcão, Eds. Cham: Springer International Publishing, 2020, pp. 437-444. https://doi. org/10.1007/978-3-030-19135-1_42

[33] J. K. Eskildsen and K. Kristensen, "The gender bias of the Net Promoter Score," in 2011 IEEE International Conference on Quality and Reliability, Sep. 2011, pp. 254-258, https:// doi.org/10.1109/icqr.2011.6031720.

[34] L. Eger and M. Mičík, "Customer-oriented communication in retail and Net Promoter Score," Journal of Retailing and Consumer Services, vol. 35, pp. 142-149, Mar. 2017, https://doi.org/10.1016/j.jretconser.2016.12.009.

[35] Y. Inal, "University students' heuristic usability inspection of the national library of Turkey website," Aslib Journal of Info Mgmt, vol. 70, no. 1, pp. 66-77, Jan. 2018, https:// doi.org/10.1108/ajim-09-2017-0216.

[36] L. Dvořáková and O. Faltejsková, "Development of Corporate Performance Management in the Context of Customer Satisfaction Measurement," Procedia - Social and Behavioral Sciences, vol. 230, pp. 335-342, Sep. 2016, https://doi.org/10.1016/j.sbspro.2016.09.042.

[37] D. A. Freedman, Statistical Models: Theory and Practice. Cambridge University Press, 2009.

[38] A. Schneider, G. Hommel, and M. Blettner, "Linear Regression Analysis," Deutsches Aerzteblatt Online, Nov. 2010, https://doi.org/10.3238/arztebl.2010.0776.

[39] H. Levene, "Robust tests for equality of variances," in Contributions to Probability and Statistics: Essays in Honor of Harold Hotelling, I. Olkin and H. Hotelling, Eds. Standford University Press, 1960, pp. 278-292.

[40] B. L. Welch, "The Ggeneralization of 'Student's' Problem When Several DifferentPopoulation Varlances Are Involved,” Biometrika, vol. 34, no. 1-2, pp. 28-35, 1947, https://doi.org/10.1093/biomet/34.1-2.28.

[41] Student, "The Probable Error of a Mean," Biometrika, vol. 6, no. 1, p. 1, Mar. 1908, doi: 10.2307/2331554. 


\section{Authors}

Atilla Wohllebe is a PhD student at the Doctoral School in Management and Organizational Sciences, Szent István University - Kaposvár Campus, Hungary. Living and working in Hamburg, Germany, he is engaged in research and professional work on consumer interactions with smartphone apps. Atilla Wohllebe holds a B.A. in Business Administration and an M.Sc. in E-Commerce.

Florian Ross is currently working on his PhD at the Doctoral School in Management and Organizational Sciences, Szent István University - Kaposvár Campus, Hungary. His research focuses on hearing aids, teleaudiology and retail. Ross currently lives in Regensburg, Germany, where he runs several hearings aids shops.

Szilárd Podruzsik is an associate professor at Corvinus University of Budapest. He works at the Institute for the Development of Enterprises. He also works as a supervisor at Kaposvár University and Szent István University. He holds a PhD from the Budapest University of Economics. His research focus is on small and mediumsized enterprises, food production, consumption and their determinants. He has already published over eighty papers as an author or co-author and participated in several research projects as a leader or participant.

Article submitted 2020-07-14. Resubmitted 2020-08-28. Final acceptance 2020-08-28. Final version published as submitted by the authors. 